\title{
A Cure for Obesity on the Horizon?
}

A review of: Air EL, Strowski MZ, Benoit SC, Conarello SL, Salituro GM, Guan XM, Liu K, Woods SC, Zhang BB 2002 Small molecule insulin mimetics reduce food intake and body weight and prevent development of obesity. Nat Med 8:179-183

$\mathrm{O}$ BESITY AND INSULIN resistance are highly prevalent in children in developed countries $(1,2)$ and pose a serious public health problem, but there are currently no effective treatments other than dietary restriction, which has a high rate of recidivism (3).

Insulin serves as a modulator of energy balance and a signal for food intake and body weight. Administration of insulin in the brain reduces food intake and body weight whereas insulin administered peripherally leads to increased body weight (4). In the study by Air et al. (5), two nonpeptidyl compounds (Cpd 1 and Cpd 2) that mediate insulin-like effects were administered to diabetic rats (Institute of Cancer Research; ICR). Intracerebroventricular $\mathrm{Cpd} 1$ one hour prior to a sucrose meal resulted in a significantly decreased intake of sucrose and chow intake in a dosedependent manner on the day following the injection. The administration of Cpd 1 was associated with increased expression of proopiomelanocortin (POMC) and decreased expression of neuropeptide Y (NPY). These two peptides produced by the hypothalamus are known to regulate food intake and body weight. This suggests that the mechanism by which Cpd 1 reduces food intake and body weight is by up-regulation of catabolic melanocortin and down regulation of anabolic NPY peptides. The reduction in body weight with Cpd 1 was not due to non-specific toxic effects such as pica, or taste aversion.

In other experiments Cpd 2 was added for seven weeks in the chow. The mice fed a high-fat diet combined with Cpd 2 had a significantly reduced rate of weight gain and adipose mass compared to the controls, and their weight gain was not statistically different from that of mice fed regular chow. This was not due to decreased food

\section{Phyllis A. Dennery}

intake. Lean body mass was comparable in all groups. Furthermore, histological analysis showed that the mice fed a high-fat diet had enlarged brown adipocytes; these were not seen with Cpd 2. The mice fed Cpd 2 did not have the high-fat induced insulinresistance, hyperinsulinemia, hyperglycemia and hyperleptinemia seen in the similarly fed controls. Additionally, no evidence of toxicity of Cpd 2 was observed.

Contrary to administration of insulin, weight loss was observed with administration of non-peptidyl insulin-like compounds. It appears paradoxical that CPD 2 given orally results in resistance to the effects of a high fat diet because it should lead to weight gain as peripheral insulin administration does. Perhaps this is due to increased central insulin-like effects. Insulin delivered to the brain activates receptors there and leads to satiety and weight loss (4). Because only a small proportion of circulating insulin can access the brain insulin receptors, peripherally administered insulin mimetics may have a greater potential to activate the brain insulin receptor cascade than peripherally administered insulin. This remains to be verified.

The authors speculate about the similarity of Cpd 2 administration to the phenotype of mice lacking the tyrosine phosphatase PTP-1B gene. These mice have a deficiency in the dephosphorylation of the insulin receptor and therefore have a sustained insulin response (6). The mice have lower circulating insulin and are more insulin sensitive than controls yet they have weight loss on a high fat diet, as with mice fed $\mathrm{Cpd}$ 2. The mechanisms for these effects are unclear although it is speculated that the animals have altered fat metabolism. Whether Cpd 2 also alters fat metabolism and whether they modify phosphorylation of the insulin receptor is not known.

The strengths of the study are that it is well controlled for dietary intake and possible confounders such as taste aversion and salt intake as well as pica. All of these would affect food intake and body weight. The study does not, however, fully evaluate or explain the mechanisms of action of the mimetics at the level of the insulin receptor. It would have been intriguing to verify whether there was truly increased Cpd 2 binding in the brain as compared to the periphery. Nonetheless, the study raises the possibility that therapeutic approaches using insulin mimetics to a control food intake, body weight, adiposity, and insulin sensitivity could provide a novel approach to the treatment of obesity and related disorders.

1. Sorof J, Daniels S 2002 Obesity hypertension in children: a problem of epidemic proportions. Hypertension 40:441-447

2. Caprio S 2002 Insulin resistance in childhood obesity. J Pediatr Endocrinol Metab 15(suppl 1):487492

3. Pinelli L, Elerdini N, Faith MS, Agnello D, Ambruzzi A, De Simone M, Leggeri G, Livieri C, Monetti N, Peverelli P, Salvatoni A, Seminara S, Uasone R, Pietrobelli A 1999 Childhood obesity: results of a multicenter study of obesity treatment in Italy. J Pediatr Endocrinol Metab 12:795-799

4. Woods SC, Lotter EC, McKay LD, Porte D Jr. 1979 Chronic intracerebroventricular infusion of insulin reduces food intake and body weight of baboons. Nature 282:503-505

5. Air EL, Strowski MZ, Benoit SC, Conarello SL, Salituro GM, Guan XM, Liu K, Woods SC, Zhang BB 2002 Small molecule insulin mimetics reduce food intake and body weight and prevent development of obesity. Nat Med 8:179-183

6. Elchebly M, Payette P, Michaliszyn E, Cromlish W, Collins S, Loy AL, Normandin D, Cheng A, HimmsHagen J, Chan CC, Ramachandran C, Gresser MJ, Tremblay ML, Kennedy BP 1999 Increased insulin sensitivity and obesity resistance in mice lacking the protein tyrosine phosphatase-1B gene. Science 283:1544-1548

Associate Professor, Pediatrics Stanford University School of Medicine Palo Alto, CA 94304, U.S.A. dennery@stanford.edu

DOI: 10.1203/01.PDR.0000063363.91000.E2 